for the dentitions of three species (Apidium phiomense; Propliopithecus chirobates; Aegyptopithecus zeuxis have permitted identification of a marked degree of sexual dimorphism (Fleagle, J. G., Kay, R. F. \& Simons, E. L. this issue of Nature p328). For each of these species, the molar teeth of the lower jaws seem to fall into uniform series, whereas the lower canines and anterior premolars show a bimodal size distribution. (The anterior lower premolar has a facet for occlusion with the upper canine and therefore reflects the degree of development of that tooth.) Of course, one must be wary of inferring sexual dimorphism in fossil material, since two separate but closely related species may be involved, and past controversies over the relationships between gracile and robust australopithecines serve as an object lesson here. Fleagle et al., to their credit, made a separate approach by considering the intraspecific coefficient of variation for the depth of the mandible, which was found to be correlated with the degree of body weight dimorphism in a sample of living primate species. On this criterion, $A$. phiomense and $A$. zeuxis were both found to be comparable to modern sexually dimorphic species such as the howler monkey, the proboscis monkey and the gorilla. It is therefore reasonable to conclude that there is good evidence for sexual dimorphism in at least three of the Fayum primate species.

The phenomenon of sexual dimorphism in body size and development of the anterior dentition in living primates has been examined in detail by several authors in recent years (Gautier-Hion, A. Mammalla 39, 365; 1975; Leutenegger, W. \& Kelley, J. T. Primates 18, 177; 1977; Clutton-Brock, T. H. \& Harvey, P. H. J. Zool. 182, 1977; Clutton-Brock T. H., Harvey, P. H. \& Rudder, B. Nature 269, 797; 1977; Harvey, P. H., Kavanagh, M. \& Clutton-Brock, T. H. J. Zool. 186, 475; 1978). The following important generaliza- tions about sexual dimorphism have emerged from these quantitative studies: (1) It is always lacking in species living in monogamous family groups; it may or may not be present in species where males have breeding access to more than one female (polygyny); (2) It tends to increase with increasing body size; (3) It is especially prevalent among terrestrial primate species; (4) It is virtually absent among living prosimian primates, uncommon in New World monkeys and markedly present only among Old World monkeys and apes.

From these generalizations it follows that the three apparently sexual dimorphic Fayum primate species were closer to modern Old World monkeys and apes than to modern New World monkeys. In the New World, notable sexual dimorphism is present only in the large-bodied howler monkeys (Alouatta spp:), with males weighing approximately $30 \%$ more than females. Yet the Fayum primates span virtually the same body size range as the modern New World monkey Family Cebidae $(600 \mathrm{~g}$ - 6kg; Kay, R.F. \& Simons, E.L. Int. J. Primatol. 1, 21; 1980) and exhibit signs of sexual dimorphism even at the lower end of that size range (Apidium phiomense). Kay and Simon (loc. cit.) have also inferred from the relatively tall molar teeth of one of the Fayum species Parapithecus grangeri, that it might have held terrestrial tendencies, though unfortunately there is insufficient dental material to show whether this species was sexually dimorphic. The prevalence of sexual dimorphism (even at quite small body sizes) and the widespread adoption of terrestrial tendencies among the Old World monkeys and apes are probably linked features, and the Fayum primates seem to fit the general pattern.

Further, it seems highly unlikely that the sexually dimorphic Fayum species lived in monogamous family groups and their social systems probably had a polygynous base, as is typical of modern Old World monkeys. Among modern New World monkeys, by contrast, monogamy is common and it has been suggested that this could have been the ancestral condition for platyrrhines. Thus, the new evidence uniformly suggests that the Fayum primates were an integral part of the evolutionary radiation of the Old World Monkeys and apes, as has been consistently maintained by Simons. One must remember, though that the common ancestor of all monkeys, apes and man must accordingly have antedated the Fayum deposits. Palaeontologists generally tend to date the origin of any group from the first known fossils, whereas incompleteness of the fossil record (particularly for Africa during the first half of the Tertiary) allows for a much earlier date. The earlier the actual date of divergence of the platyrrhines and catarrhines, the greater is the likelihood of an African origin of the higher primates.

An understanding of the the relationship between primate sexual dimorphism and social organization is of considerable interest and enables us to suggest the kind of social groups that fossil primates may have lived in. Explanations of why sexual dimorphism evolved have, hitherto, invoked two male-oriented causative influences: (1) intense male-male competition for females, and (2) defence of the social group against predators by large males. However, sexual dimorphism involves divergent male and female strategies and little attention has been given to factors which might favour small body size in females. In an elegant analysis of dental sexual dimorphism in primates, Harvey et al. $(1978$, loc. cit.) used relationships between female tooth size and body size as baselines for assessing male dental development ('relative male tooth size') and were able to analyse more precisely the factors associated with exaggerated development

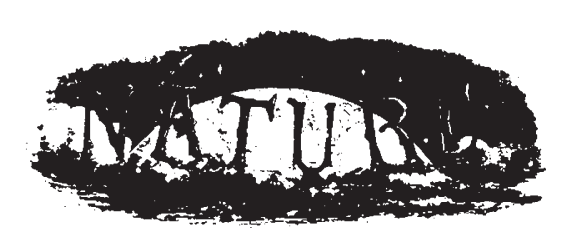

\section{PHYSICS WITHOUT APPARATUS}

Acoustical expertments require, for the most part, the aid of some good instrument or valuable piece of apparatus. Nevertheless a few instructive illustrations of the principles of the science can be improvised without difficuly. Firstly, there is the familiar experiment brought into fashion, we believe, by Prof. Tyndall, of setting a row of ivory billiard balls or glass solitaire marbles along a groove between two wooden boards, and showing how their elasticity enables them to transmit from one to another a wave of moving energy imparted to the first of the row, thus affording a type of the transmission of sound-waves from particle to particle through elastic media. Then we may show how sounds travel through solid bodies by resting against a music-box or other musical instrument, a broomstick, or any convenient rod of wood, at the other end of which we place our ear. A kindred experiment, illustrative of the transmission of sounds through threads, is depicted in the Figure. A large spoon is tied to the middle of a thin silken or hempen thread, the ends of which are thrust into the ears upon the ends of the thumbs. If the spoon be dangled against the edge of the table it will resound, and the tones reach the ear like a loud church bell. The thread telephone or "lover's telegraph," is upon the same principle, the thread transmitting the whispered words to a distance, without that loss by spreading in all directions which takes place in the open air.

From Nature 22, 23 September, 488, 1880.

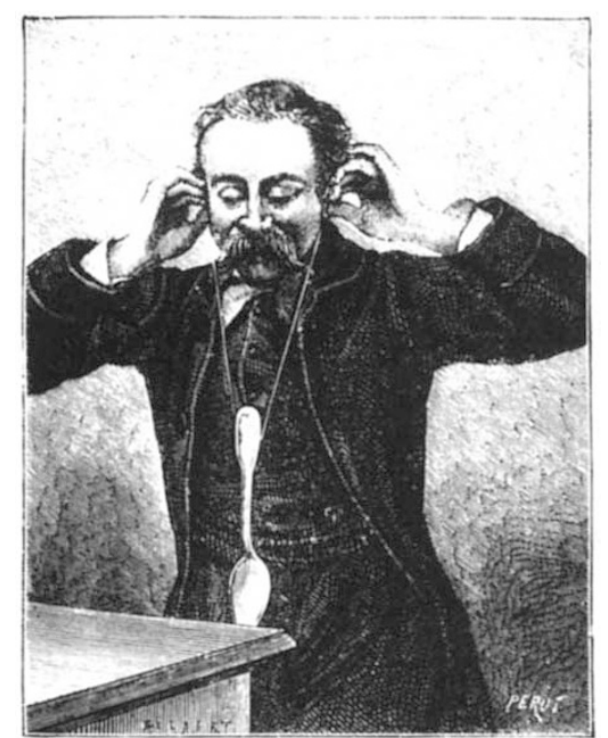

